\title{
Households' Choice of Genotypes and Traits of Preference in Yoruba Ecotype Chicken in Ibadan, Nigeria
}

\author{
Popoola Moshood Abiola ${ }^{1}$, Lamidi Luqman O. ${ }^{1}$, Raji Ademola Moshood ${ }^{1}$, Adebisi Gbadebo Luqman ${ }^{1}$, Onuoha \\ Chinyere Joy ${ }^{1} \&$ Olaoye Ridwan Oyebamiji ${ }^{1}$ \\ ${ }^{1}$ Federal College of Animal Health and Production Technology, Ibadan, Nigeria \\ Correspondence: Popoola Moshood Abiola, Federal College of Animal Health and Production Technology, Ibadan, \\ Nigeria. Tel: 234-703-458-4168. E-mail: moshood.popoola@fcahptib.edu.ng
}

Received: January 13, 2020 Accepted: February 14, 2020 Online Published: March 5, 2020

\begin{abstract}
This study aimed at evaluating Yoruba Ecotype chicken genotypes of choice and traits of preference in the chicken by households in Ibadan, Nigeria. Data were obtained from a total of 120 households using structured interview schedule. Data were subjected to both descriptive statistics and Principal Components Analysis (PCA). Results revealed that most of the respondents were female; they raised the chicken for income generation and consumption. Most of the respondents preferred normal feather Yoruba Ecotype chicken to other genotypes. The result also revealed that traits of preference by most of the respondents were growth rate, body size, egg production, fertility, disease resistance, temperament, broodiness, mothering ability, hatchability, plumage colour and distribution, social-cultural value, survivability, fecundity, ease of sales and laying of large number of eggs. The Principal component 1 explained over $86.2 \%$ in household preferences for all the variables considered in the study. Based on the result of this study, it was concluded that most of the respondents' preferred normal feather Yoruba Ecotype chicken compared to other genotypes like frizzle feather and naked neck. Traits of economic importance appeared to be consistent in preference for genotype of choice by respondents. The PCI value explained over $86.2 \%$ in household preferences for all the variables. Further research efforts on genotypes and traits of economic importance of Yoruba Ecotype chicken could facilitate future breeding programs geared towards increasing the chicken production and productivity among households and smallholders. There is also a need for effective breeding and conservation program to preserve economically important genetic resources of this chicken to prevent the risk of loss of the indigenous chicken genetic pool.
\end{abstract}

Keywords: chicken, ecotype, indigenous, preference, traits

\section{Introduction}

Poultry, particularly chickens are the most widely kept livestock species in the world and also the most numerous (Perry et al; 2002; Moreki et al., 2010). In Africa, indigenous chicken make over $70 \%$ of the total chicken population (FAO, 1986). Indigenous chicken in Africa are in general hardy, adaptive to rural environment, survive on little or no input and adjust to fluctuations in feed availability. Chicken largely dominate flock composition and make up about $98 \%$ (Gueye, 2003) of the total poultry members (chickens, ducks and turkeys) kept in Africa. Indigenous chicken constitutes $80 \%$ of the 120 million poultry type raised in the rural areas in Nigeria (RIM,1992). They are self-reliant and hardy birds with the capacity to withstand harsh weather condition and adaptation to adverse environment. They are known to possess qualities such as ability to hatch on their own, brood and scavenge for major parts of their food and possess appreciated immunity from endemic diseases (RIM, 1992).

There are various ecotypes of the local chicken in different agro ecological zones in Nigeria as reported by different authors. Olori (1992) noted two ecotypes characterized as forest and savannah or Yoruba and Fulani ecotypes respectively. Nwosu (1979) identified three main strains in ecotype named Nsukka, Owerri and Awgu types at the south eastern states of Nigeria. Recent works revealed that the different ecotypes can be grouped into two major categories on the basis of body size and body weight as heavy ecotype and light ecotype (Momoh et al; 2007).The heavy ecotype (also referred to as Fulani ecotype) is found in the dry savannahs (Guinea and Sahel savannah).The light ecotypes are those chicken types from the swamp, rain forest and derived savannah agro ecological zones whose mature body weight ranges between $0.68-1.5 \mathrm{~kg}$. Yoruba ecotype is made up of four strains which are normal feather, frizzle feather, necked neck and frey.

In Nigeria, indigenous chickens were characterized along genetic lines of feather and plumage colour (such as 
normal or frizzled feathered), body structure (such as naked neck, dwarf types and colour variants such as black, white, brown, mottled). The frequency distribution of the normal feathered chicken were about $91.8 \%$ while that of frizzled and naked neck were 5.2 and 3.0\% respectively in Bayelsa state, Nigeria (Ajayi and Agaviezor, 2009). There are wide range of factors responsible for preference of Yoruba ecotype chicken strains among households raising them. Knowledge of trait preferences for breeding decisions is central to the formulation of livestock policies aimed at improving the livelihoods of smallholder chicken farmers (Yakubu et al., 2019). Thus, this study was conducted to evaluate the preference for choice of strains of Yoruba Ecotype chicken raised among households in Ibadan, Nigeria.

\section{Method}

\subsection{Area of the Study}

The study was conducted in Ibadan, the capital city of Oyo State, with a population of over 3 million people. It is made up of 11 Local Government Areas (LGAs). Ibadan is the largest metropolitan geographical area in Nigeria. There are several cattle ranches, a dairy farm as well as a commercial abattoir in Ibadan; these, coupled with other reasons such as favourable climatic condition, economy of the city (being the third cheapest city to live in Nigeria), largest metropolitan, have made Ibadan to be a strategic location where appreciable number of livestock such as cattle, chicken, sheep and goat can be found.

\subsection{Data Collection}

The target population of the study were households raising indigenous (Yoruba Ecotype) chicken. These households were selected randomly in the study area to select 120 respondents. Interview schedule was used to obtain information from these respondents; information collected include, socio-economic characteristics of the respondents, chicken production characteristics and traits of preference in the chicken by these respondents.

\subsection{Statistical Analyses}

Data were subjected to both descriptive statistics such as (mean, frequency and percentage) and Principal Components Analysis (PCA) using SPSS (V.22)

\section{Results}

Table 1 shows the results of socio-economic characteristics of the respondents. Result shows that most of the respondents were within the age range of 25-29 (27.5\%). The mean age of the respondents was 28.4 years. The result of this study indicates that majority of the respondents are still in their economical active ages as reported by Akinbile, (1994); Popoola et al., (2017). Result showed that majority of the respondents were female (63.3\%), while $36.7 \%$ of them were male. This implies that more women are involved in rearing of indigenous chicken than their male counterparts in the study area. This could be attributed to small body size of chicken and ease of handling unlike other large animals like cattle which may be difficult to handle by women. According to Gueye, (2000), about $80 \%$ of chicken in some African countries are owned and controlled by women; Badubi (2000) also reported that about $98 \%$ of chicken in rural areas are managed by women and only the remaining $2 \%$ are owned by men. Marshall et al. (2016) reported that gender differences may result from production objectives and the specific roles and responsibilities of males and females in traditional livestock rearing. Abubakar et al., (2007) observed that in most Nigerian households, chicken belong to the entire family with women owning majority of the birds, followed by children and men being the last. The result implies that more than half of the respondents were married (62.5\%) and this is expected considering the age group of most of the respondents in this study. Odebode and Popoola (2016) reported similar report that at older age, individuals are expected to have been married. Most of the respondents had tertiary education $(46.7 \%)$, followed by those who had secondary education $(38.3 \%)$ which implies that most of them can read and write. Thus, this will enhance better communication as well as adoption of innovation. The result revealed that most of the respondents were Christians (53.3\%), followed by those who were Muslims (43.3\%), and (3.4\%) of the respondent were traditionalists. Analysis of profile of the respondents as regards their beliefs or religious group implies that there is no religious taboo on raising of indigenous chicken among the respondents. The result shows that majority of respondents had household size between $2-5$ people $(58.3 \%)$; the mean household size of the respondents was 4 members. This result agrees with result of Bameke (2003) who reported household size of between 2-6 people as the modal family size among households. Most of the respondents were traders $(37.5 \%)$, while other occupations like farming $(29.2 \%)$, civil service $(15.0 \%)$ and artisans (18.3\%) were practiced by the respondents. This implies that respondents are not involved in one income generating activities, but rather in different ones as means of increasing their income so as to improve their livelihood. Majority of the respondents earned between $\$ 18,000$ - $\$ 23,000$ (42.5\%). The remarkable difference in 
income realized is due to differences in the primary occupation of the responds (Popoola et al., 2017 ). The mean income of the respondents was $\$ 23,145.02$.

Table 1. Distribution of socio-economic characteristics of the respondents

\begin{tabular}{|c|c|c|c|}
\hline Variable & Frequency & Percentage & Mean \\
\hline \multicolumn{4}{|l|}{ Age (years) } \\
\hline$<20$ & 2 & 1.7 & \\
\hline $20-24$ & 24 & 20.0 & \\
\hline $25-29$ & 33 & 27.5 & \\
\hline $30-34$ & 23 & 19.2 & 28.4 \\
\hline $35-39$ & 15 & 12.5 & \\
\hline$>39$ & 23 & 19.2 & \\
\hline \multicolumn{4}{|l|}{ Sex } \\
\hline Male & 44 & 36.7 & \\
\hline Female & 76 & 63.3 & \\
\hline \multicolumn{4}{|l|}{ Marital status } \\
\hline Single & 39 & 32.5 & \\
\hline Married & 75 & 62.5 & \\
\hline Divorced & 1 & 0.8 & \\
\hline Widowed & 5 & 4.2 & \\
\hline \multicolumn{4}{|l|}{ Other occupation } \\
\hline Civil service & 18 & 15.0 & \\
\hline Farming & 35 & 29.2 & \\
\hline Trading & 45 & 37.5 & \\
\hline Artisan & 22 & 18.3 & \\
\hline \multicolumn{4}{|l|}{ Religion } \\
\hline Islam & 52 & 43.3 & \\
\hline Christianity & 64 & 53.3 & \\
\hline Traditional & 4 & 3.3 & \\
\hline \multicolumn{4}{|l|}{ Educational level } \\
\hline Non formal education & 11 & 9.2 & \\
\hline Primary education & 7 & 5.8 & \\
\hline Secondary education & 46 & 38.3 & \\
\hline Tertiary education & 56 & 46.7 & \\
\hline \multicolumn{4}{|l|}{ Household size } \\
\hline $2-5$ & 70 & 58.3 & \\
\hline $6-9$ & 42 & 35.0 & 4 \\
\hline $10-13$ & 7 & 5.8 & \\
\hline Above 13 & 1 & 0.8 & \\
\hline \multicolumn{4}{|l|}{ Income } \\
\hline$\$ 18000-\$ 23000$ & 51 & 42.5 & \\
\hline$\$ 24000-\$ 29000$ & 21 & 17.5 & \\
\hline$\$ 30000-\$ 35000$ & 16 & 13.3 & $23,145.02$ \\
\hline$\$ 35000$ - $\$ 40000$ & 5 & 4.2 & \\
\hline Above 40000 & 27 & 22.5 & \\
\hline
\end{tabular}

Indigenous chicken production enterprise of the respondents is presented in Table 2. The result revealed that respondents' purpose of production were majorly for income generation $(41.7 \%)$ followed by consumption (36.7\%), income and consumption (19.2\%) and the least was for research $(2.5 \%)$. This is an indication that rearing of chicken can serve the purpose of generating immediate cash for household members. Ondwassy et al., (2005) reported that rearing of indigenous chicken is a relevant tool in the eradication of poverty in rural areas. Chicken serves as an investment and source of security for households in addition to their use as source of meat and eggs for consumption and income (Muchadeyi et al; 2007). Result also shows that most of strain of the chicken raised by respondents were normal feather $(61.7 \%)$ followed by those who raised normal feather, frizzle feather and 
naked neck (11.6\%), normal feather and frizzle feather (9.2\%), normal feather and naked neck (5.8\%), only frizzle feather $(5.0 \%)$, only naked neck $(4.2 \%)$, frizzle feather and naked neck. $(2.5 \%)$. The result implies that normal feathered chicken is the most abundant strain of Yoruba Ecotype chicken raised by the respondents. This could be due to its appearance unlike other strains with appearance that may not be appealing to these respondents. The result further revealed that most of the respondents' flock size were 6-10 (27.5\%) followed by 11-15 (20.8\%), 15 (19.2\%), 16-20 (18.3\%) and above 20 (14.2\%) chicken.

Table 2. Chicken production characteristics of the respondents

\begin{tabular}{llll}
\hline \multicolumn{1}{c}{ Variables } & Frequency & Percentage & Mean \\
\hline Purpose of production & & & \\
Income generation & 50 & 41.7 \\
Research & 3 & 2.5 & \\
Consumption & 44 & 36.7 \\
Income and consumption & 23 & 19.2 & \\
Strain of the chicken & & & \\
& & & \\
Normal feather & 74 & 61.7 \\
Frizzle feather & 6 & 5.0 & \\
Naked neck & 5 & 4.2 & \\
Normal feather and frizzle feather & 11 & 9.2 & \\
Normal feather and naked neck & 7 & 5.8 & \\
Frizzle feather and naked neck & 3 & 2.5 & \\
Normal feather, frizzle feather and naked neck & 14 & 11.6 \\
Flock size & & & \\
$1-5$ & 23 & 19.2 \\
$6-10$ & 33 & 27.5 \\
$11-15$ & 25 & 20.8 \\
$16-20$ & 22 & 18.3 \\
Above 20 & 17 & 14.2 & \\
\hline
\end{tabular}

Preference of respondents for genotype of Yoruba Ecotype chicken is presented in Fig. 1; result showed that most of the respondents preferred normal feather chicken (46\%); followed by preference for frizzle feather (32\%) and the least preferred genotype of Yoruba Ecotype chicken by the respondents was the naked neck $(22 \%)$. Respondents' choice of particular genotype may be attributed to poultry keeping objectives and varied importance attached to such genotype. 


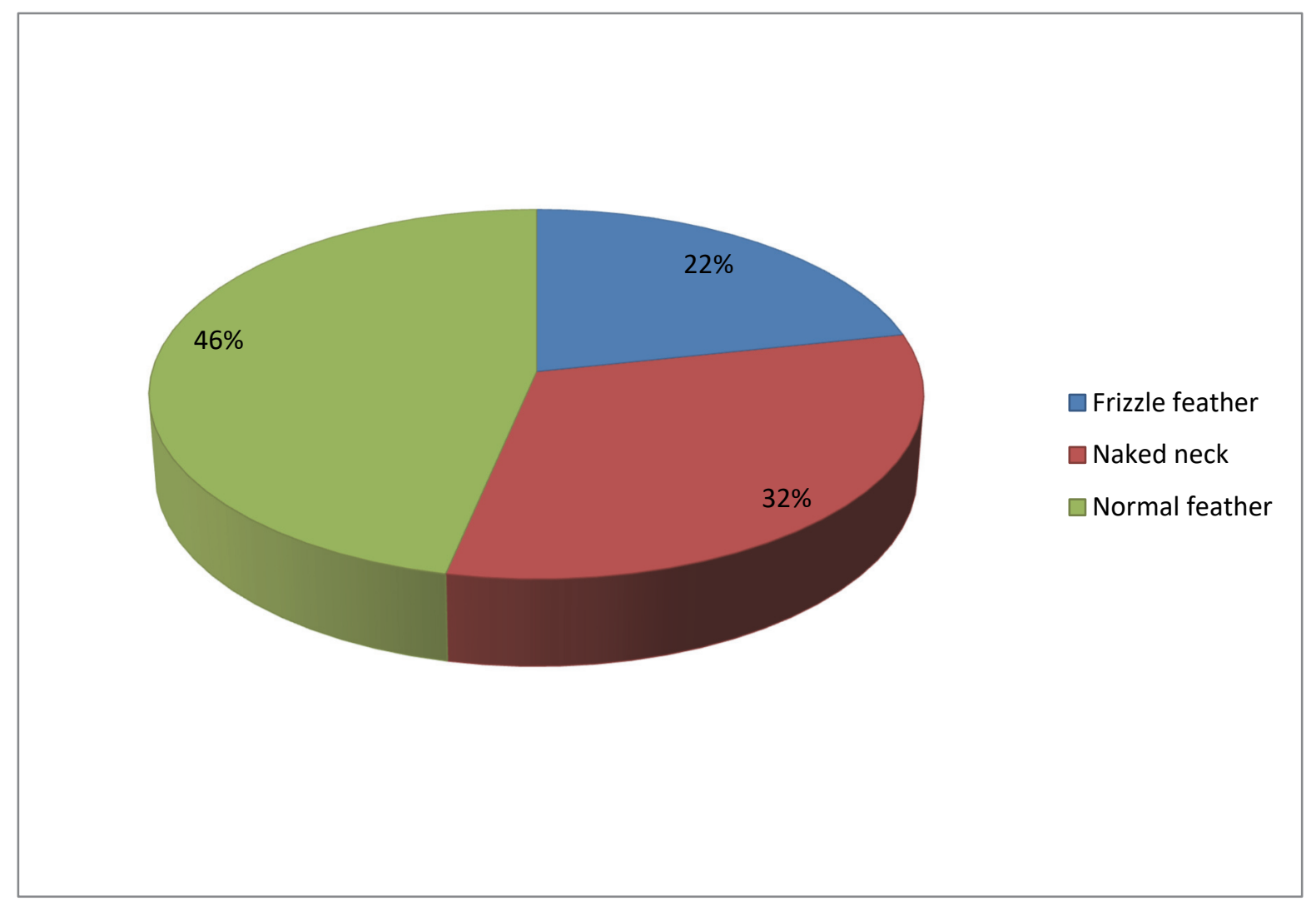

Fig. 1. Respondents' preference for genotype of Yoruba Ecotype chicken

Table 3 showed the quality attributes of Yoruba ecotype chicken genotype as preferred by respondents. Result showed that growth rate (30.8\%), plumage colour (24.2\%), survivability (27.5\%), plumage distribution (27.5\%), appearance $(32.5 \%)$, acceptability $(26.7 \%)$, ability to protect chicks from predators $(24.2 \%)$ and ease of sales $(25.8 \%)$ were the most preferred traits by the respondents in the preferred genotype (normal feather) of Yoruba Ecotype chicken of their choice. Result further revealed that body size (30.8\%), egg production $(27.5 \%)$, fertility (26.7\%), disease resistance (40.8\%), temperament (24.4\%) , broodiness $(26.7 \%)$, mothering ability (30\%), hatchability $(27.5 \%)$, social- cultural purpose $(43.3 \%)$, fecundity $(27.5 \%)$ and ability to lay eggs in large number (29.2\%) were the preferred traits by respondents in the preferred genotype of Yoruba Ecotype chicken of their choice. However, heat tolerance $(36.7 \%)$ was the most preferred trait by respondents who chose to raise frizzle feather Yoruba Ecotype chicken. The result of this study implies that respondents had reasons for choice of their preferred genotype of the chicken based on specific traits possessed by different genotypes of the chicken. Some of the merits indicated by farmers for the choice of a particular genotype in the current study are similar to the egg productivity, body size and fast growth traits reported by Sisay et al. (2018) and Mahoro et al. (2018). The choice of preferred genotypes by respondents may be attributed to poultry keeping objectives and varied importance attached to the genotype of choice by respondents. Terfa et al., (2019) reported the magnitude of plumage colour which is more pronounced than productive traits of importance in chicken. Faustin et al., (2010) reported preference for disease resistance traits of chickens which may be a consequence of economic importance of poultry diseases. For the traits of chickens, Terfa et al., (2019) reported good mothering ability, diseases resistance, good meat and egg taste, large body size, larger number of eggs per clutch, and white plumage color in order of prioritization as traits of preference in chicken genotypes. In a similar study, Yakubu et al (2019) reported that the preference for body size and the high ranking of egg number, egg size, meat taste, and ease of sales was connected to their direct monetary values as consumers may be willing to pay premium with a unit increase in the traits. The authors further noted that the easier the sales of the birds, the more the income also generated. Heat tolerance is another valuable attribute preferred and should be considered in selection of indigenous chicken since domestic chicken become easily susceptible to heat or cold environmental stress (Ramnath et al; 2007). 
Table 3. Quality attributes of Yoruba ecotype chicken genotype as preferred by respondents

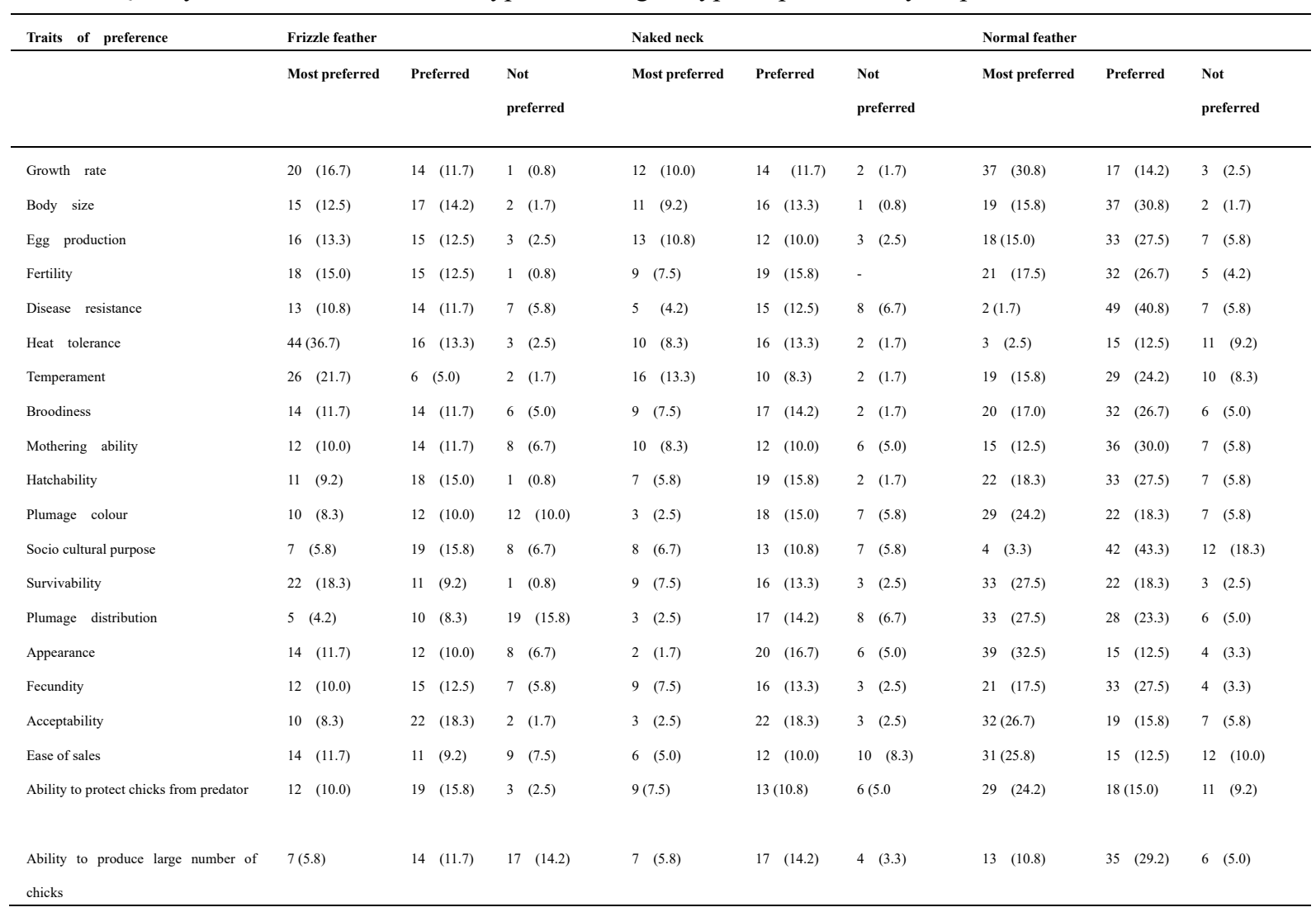

Table 4 shows the Eigen values and variance obtained from principal component analysis (PCA) which indicated that 11 principal components (PC) affect households' preferences on chicken traits. The PCI value explained over $86.2 \%$ in household preferences for all the variables, Principal component 2,3,4,5,6,7,8,9,10 and 11 had low variance ranging from $2.3 \%, 1.9 \%, 1.5 \%, 1.2 \%, 1.2 \%, 0.9 \%, 0.9 \%, 0.7 \%, 0.6 \%$ and $0.5 \%$. This implies that the high variance (86.2\%) of traits possessed by the chicken were mostly preferred by the households, while the low variance of PC2-PC11 implies that some of the traits possessed by the chicken were preferred by the households. According to Ajayi et al. (2012); Lopes et al., (2013) PCA can be used for ranking and grouping and to explore the relationship between traits in a dataset (Pinto et al. 2006).

Table 4. Eigen values and variance obtained from principal components analysis (PCA)

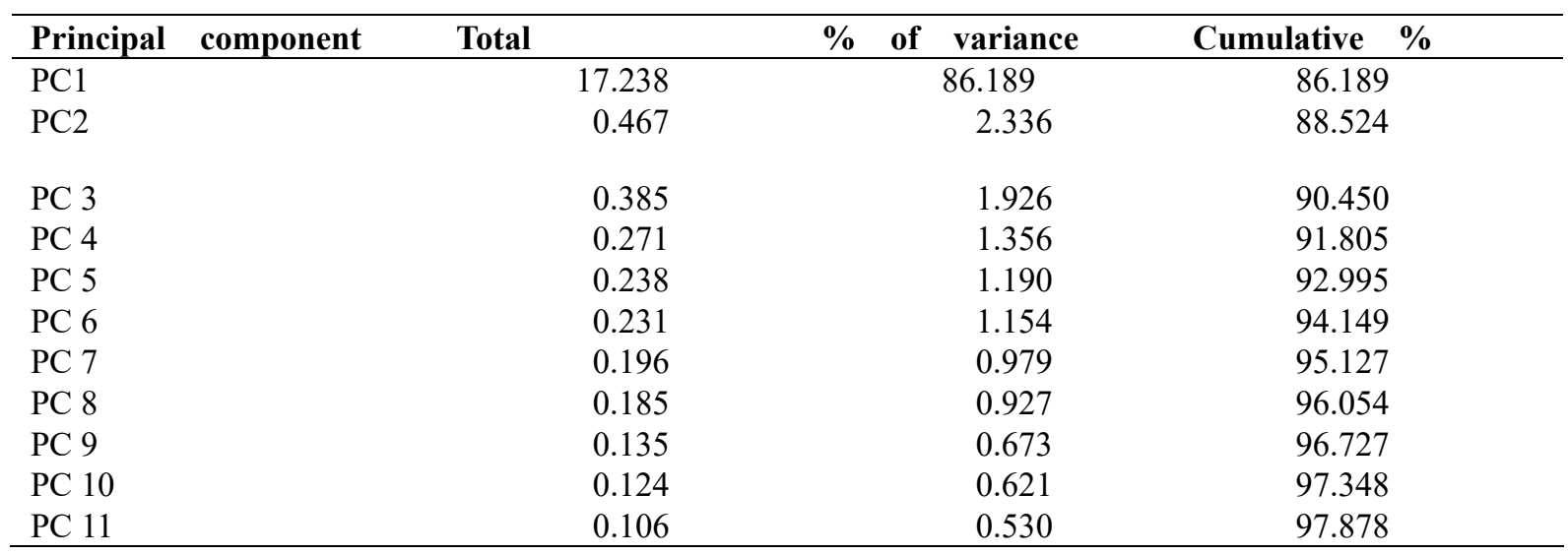

PC - Principal Component 


\section{Conclusion}

Based on the result of this study, most of the respondents' preferred normal feather Yoruba Ecotype chicken compared to other genotypes like frizzle feather and naked neck. Traits of economic importance appeared to be consistent in preference for genotype of choice by respondents. The PCI value explained over $86.2 \%$ in household preferences for all the variables. Further research efforts on genotypes and traits of economic importance of Yoruba Ecotype chicken could facilitate future breeding programs geared towards increasing the chicken production and productivity among households and smallholders. There is also the need for effective breeding and conservation program to preserve economically important genetic resources of these chicken to prevent the risk of loss of the indigenous chicken genetic pool.

\section{Conflict of interest}

There is no conflict of interest among the authors of this study. Thus, all authors agreed on its publication.

\section{References}

American Psychological Association. (1972). Ethical standards of psychologists. Washington, DC: American Psychological Association.

Anderson, C. A., Gentile, D. A., \& Buckley, K. E. (2007). Violent video game effects on children and adolescents: Theory, research and public policy. https://doi.org/10.1093/acprof:oso/9780195309836.001.0001

Beck, C. A. J., \& Sales, B. D. (2001). Family mediation: Facts, myths, and future prospects (pp. 100-102). Washington, DC: American Psychological Association. https://doi.org/10.1037/10401-000

Bernstein, T. M. (1965). The careful writer: A modern guide to English usage (2nd ed.). New York, NY: Atheneum.

Bjork, R. A. (1989). Retrieval inhibition as an adaptive mechanism in human memory. In H. L. Roediger III, \& F. I. M. Craik (Eds.), Varieties of memory \& consciousness (pp. 309-330). Hillsdale, NJ: Erlbaum.

Cress, C. M. (2009). Curricular strategies for student success and engaged learning [PowerPoint slides]. Retrieved from http://www.vtcampuscompact.org/2009/TCL_post/presenter_powerpoints /Christine\%20Cress\%20-\%20Curricular\%20Strategies.ppt

Driedger, S. D. (1998, April 20). After divorce. Maclean's, 111(16), 38-43.

Gibbs, J. T., \& Huang, L. N. (Eds.). (1991). Children of color: Psychological interventions with minority youth. San Francisco, CA: Jossey-Bass.

Gilbert, D. G., McClernon, J. F., Rabinovich, N. E., Sugai, C., Plath, L. C., Asgaard, G., ... Botros, N. (2004). Effects of quitting smoking on EEG activation and attention last for more than 31 days and are more severe with stress, dependence, DRD2 A 1 allele, and depressive traits. Nicotine and Tobacco Research, 6, 249-267. https://doi.org/10.1 080/1462220041 0001676305

Goleman, D. (2009). What makes a leader? In D. Demers (Ed.), AHSC 230: Interpersonal communication and relationships (pp. 47-56). Montreal, Canada: Concordia University Bookstore. (Reprinted from Harvard Business Review, 76(6), pp. 93-102, 1998).

Guignon, C. B. (1998). Existentialism. In E. Craig (Ed.), Routledge encyclopedia of philosophy (Vol. 3, pp. 493502). London, England: Routledge.

Healey, D. (2005). Attention deficit/hyperactivity disorder and creativity: An investigation into their relationship (Unpublished doctoral dissertation). University of Canterbury, Christchurch, New Zealand.

Herculano-Houzel, S., Collins, C. E., Wong, P., Kaas, J. H., \& Lent, R. (2008). The basic nonuniformity of the cerebral cortex. Proceedings of the National Academy of Sciences, 105, 12593-12598. https://doi.org/10.1073/pnas.0805417105

Klimoski, R., \& Palmer, S. (1993). The ADA and the hiring process in organizations. Consulting Psychology Journal: Practice and Research, 45(2), 10-36. https://doi.org/10.1037/1061-4087.45.2.10

Kubrick, S. (Director). (1980). The Shining [Motion picture]. United States: Warner Brothers.

Liu, S. (2005, May). Defending against business crises with the help of intelligent agent based early warning solutions. Paper presented at the Seventh International Conference on Enterprise Information Systems, Miami, FL. Abstract retrieved from http://www.iceis.org/iceis2005/abstracts_2005.htm

MacIntyre, L. (Reporter). (2002, January 23). Scandal of the Century [Television series episode]. In H. Cashore (Producer), The fifth estate. Toronto, Canada: Canadian Broadcasting Corporation. 
McLuhan, M. (1970a). Culture is our business. New York, NY: McGraw-Hill.

McLuhan, M. (1970b). From cliche to archetype. New York, NY: Viking Press.

Mellers, B. A. (2000). Choice and the relative pleasure of consequences. Psychological Bulletin, 126, $910-924$. https://doi.org/10.1037/0033-2909.126.6.910

Postman, N. (1979). Teaching as a conserving activity. New York, NY: Delacorte Press.

Postman, N. (1985). Amusing ourselves to death: Public discourse in the age of show business. New York, NY: Viking.

Semenak, S. (1995, December 28). Feeling right at home: Government residence eschews traditional rules. Montreal Gazette, p. A4.

Strong, E. K. Jr., \& Uhrbrock, R. S. (1923). Bibliography on job analysis. In L. Outhwaite (Series Ed.), Personnel Research Series: Vol. 1. Job analysis and the curriculum (pp. 140-146). https://doi.org/10.1037/10762-000

\section{Copyrights}

Copyright for this article is retained by the author(s), with first publication rights granted to the journal.

This is an open-access article distributed under the terms and conditions of the Creative Commons Attribution license (http://creativecommons.org/licenses/by/4.0/). 